\title{
Risk of biochemical recurrence based on extent and location of positive surgical margins after robot-assisted laparoscopic radical prostatectomy
}

Gautier Marcq ${ }^{1,2}$, Aude Michelet ${ }^{3}$, Gerjon Hannink ${ }^{4}$, Jerome Rizk ${ }^{1}$, Jean Sauvain ${ }^{5}$, Arnauld Villers ${ }^{1}$, Mo Saffarini ${ }^{3^{*}}$ (D) and Charles H. Rochat ${ }^{5}$

\begin{abstract}
Background: There are no published studies on the simultaneous effect of extent and location of positive surgical margins (PSMs) on biochemical recurrence (BCR) after robot-assisted laparoscopic prostatectomy (RALP). The aim was to report the incidence, extent, and location of PSMs over the inclusion period as well as the rates of BCR and cancer-related mortality, and determine if BCR is associated with PSM extent and/or location.
\end{abstract}

Methods: Retrospective review of 530 consecutive patients who underwent RALP between 2003 and 2012. KaplanMeier (KM) survival analyses and Cox regressions were performed to determine variables associated with BCR.

Results: For the 530 operated patients, evaluated at a median of 92 months (IQR, 87-99), PSMs were observed in 156 (29\%), of which 24\% were focal. Out of 172 PSMs, 126 (73\%) were focal and 46 (27\%) were extensive. The KM survival using BCR as endpoint was $0.81(\mathrm{Cl}, 0.78-0.85)$ at 5 years and was $0.67(\mathrm{Cl}, 0.61-0.72)$ at 10 years; and using cancerrelated mortality as endpoint was $0.99(\mathrm{Cl}, 0.99-1.00)$ at 5 years and $0.95(\mathrm{Cl}, 0.92-0.98)$ at 10 years. Multi-variable analysis revealed the strongest predictors of $\mathrm{BCR}$ to be Gleason score $\geq 8(\mathrm{HR}=7.97 ; \mathrm{Cl}, 4.38-14.51)$ and $4+3$ $(H R=3.88 ; \mathrm{Cl}, 2.12-7.07)$, lymph nodes invasion ( $\mathrm{HR}=3.42 ; \mathrm{Cl}, 1.70-6.91)$, pT stage $3 \mathrm{~b}$ or $4(\mathrm{HR}=3.07 ; \mathrm{Cl}, 1.93-4.90)$, and extensive apical PSMs ( $\mathrm{HR}=2.62 ; \mathrm{Cl}, 1.40-4.90)$ but not focal apical PSMs ( $\mathrm{HR}=0.86 ; \mathrm{Cl}, 0.49-1.50 ; p=0.586)$.

Conclusion: Extensive apical PSMs significantly increased the risk of BCR, independently from pT stage, Gleason score and lymph nodes invasion, while focal apical PSMs had no significant effect on BCR.

Keywords: Prostate cancer, Prostatectomy, Robot-assisted, Laparoscopy, Biochemical recurrence, Positive surgical margins

\section{Background}

Positive surgical margins (PSMs) following radical prostatectomy are adverse outcomes, associated with the risk of biochemical recurrence (BCR) [1, 2]. Recent studies report a wide range of PSM incidence (12-39\%) [3-8] which depends on tumor size, stage and localization, as well as surgeon experience [6, 9], and surgical approach $[3,10,11]$.

The impact of PSM status on BCR is controversial: First, multifocal PSMs indicate that there is more cancer tissue left behind, but are not always associated with an increased

\footnotetext{
* Correspondence: journals@resurg.eu

${ }^{3}$ ReSurg SA, chemin de la Vuarpillière 35, 1260 Nyon, Switzerland Full list of author information is available at the end of the article
}

risk of BCR [10-17]. Second, extensive PSMs increase the risk of $\mathrm{BCR}[2,14,15]$, even if the lack of consensus in reporting extent does not allow firm conclusions [1]. Third, apical and posterolateral PSMs are believed to present a greater risk of $\mathrm{BCR}$ than other locations $[4,5,15,18]$, though numerous studies found that location does not affect prognosis $[4,19]$. Whatever their oncologic implications, PSMs often cause anxiety in affected patients, and could prompt adjuvant radiotherapy [2].

While some studies investigated the associations between BCR and PSM extent and location $[4,5]$, none considered their simultaneous effect. The authors therefore aimed to: (i) report the variations of incidence, extent, and 
Table 1 Demographics, preoperative and pathological data

\begin{tabular}{|c|c|c|c|c|c|c|c|}
\hline \multirow{3}{*}{ Follow-up (months) - median (IQR) } & \multirow{2}{*}{\multicolumn{2}{|c|}{$\begin{array}{l}\text { Total } \\
n=530\end{array}$}} & \multirow{2}{*}{\multicolumn{2}{|c|}{$\frac{\text { Evaluated }}{c}$}} & \multirow{2}{*}{\multicolumn{2}{|c|}{$\frac{\text { Lost to FU }}{n=77}$}} & \multirow[t]{3}{*}{$p$-value } \\
\hline & & & & & & & \\
\hline & & & 92 & $(87-99)$ & 47 & $(29-87)$ & \\
\hline \multicolumn{8}{|l|}{ Preoperative data } \\
\hline Age (years) - median (IQR) & 63 & $(58-68)$ & 63 & $(59-68)$ & 61 & $(56-66)$ & 0.028 \\
\hline Preoperative PSA - median (IQR) & 6.4 & $(4.8-9.0$ & 6.6 & $(4.9-9.0)$ & 6.0 & $(4.7-9.2)$ & 0.628 \\
\hline CT stage & & & & & & & 0.019 \\
\hline$T 1(a, b, c)$ & 199 & $(38 \%)$ & 175 & $(39 \%)$ & 24 & $(31 \%)$ & \\
\hline$T 2 a$ & 106 & $(20 \%)$ & 82 & $(18 \%)$ & 24 & $(31 \%)$ & \\
\hline$T 2 b$ & 155 & $(29 \%)$ & 136 & $(30 \%)$ & 19 & $(25 \%)$ & \\
\hline $\mathrm{T} 2 \mathrm{C}$ & 52 & $(10 \%)$ & 48 & $(11 \%)$ & 4 & $(5 \%)$ & \\
\hline T3 & 11 & $(2 \%)$ & 9 & $(2 \%)$ & 2 & $(3 \%)$ & \\
\hline unknown & 7 & $(1 \%)$ & 3 & $(1 \%)$ & 4 & $(5 \%)$ & \\
\hline D'Amico risk group & & & & & & & 0.005 \\
\hline low & 225 & $(42 \%)$ & 205 & $(45 \%)$ & 20 & $(26 \%)$ & \\
\hline intermediary & 196 & $(37 \%)$ & 152 & $(34 \%)$ & 44 & $(57 \%)$ & \\
\hline high & 97 & $(18 \%)$ & 85 & $(19 \%)$ & 12 & $(16 \%)$ & \\
\hline unknown & 12 & $(2 \%)$ & 11 & $(2 \%)$ & 1 & $(1 \%)$ & \\
\hline Nerve sparing & & & & & & & 0.471 \\
\hline unilateral & 13 & $(2 \%)$ & 12 & (3\%) & 1 & $(1 \%)$ & \\
\hline bilateral & 498 & $(94 \%)$ & 429 & $(95 \%)$ & 69 & $(90 \%)$ & \\
\hline unknown & 19 & $(4 \%)$ & 12 & $(3 \%)$ & 7 & $(9 \%)$ & \\
\hline \multicolumn{8}{|l|}{ Pathological results } \\
\hline Pathological Gleason Score & & & & & & & 0.005 \\
\hline$\leq 6$ & 214 & $(40 \%)$ & 171 & $(38 \%)$ & 43 & $(56 \%)$ & \\
\hline $3+4$ & 178 & $(34 \%)$ & 159 & $(35 \%)$ & 19 & $(25 \%)$ & \\
\hline $4+3$ & 73 & $(14 \%)$ & 64 & $(14 \%)$ & 9 & $(12 \%)$ & \\
\hline$\geq 8$ & 58 & $(11 \%)$ & 55 & $(12 \%)$ & 3 & $(4 \%)$ & \\
\hline unknown & 7 & $(1 \%)$ & 4 & $(1 \%)$ & 3 & $(4 \%)$ & \\
\hline pT stage & & & & & & & 0.004 \\
\hline pT2 & 385 & $(73 \%)$ & 321 & $(71 \%)$ & 64 & $(83 \%)$ & \\
\hline pT3a & 80 & $(15 \%)$ & 75 & $(17 \%)$ & 5 & $(6 \%)$ & \\
\hline pT3b & 56 & $(11 \%)$ & 52 & $(11 \%)$ & 4 & $(5 \%)$ & \\
\hline pT4 & 2 & $(0 \%)$ & 2 & $(0 \%)$ & 0 & $(0 \%)$ & \\
\hline unknown & 7 & $(2 \%)$ & 3 & $(1 \%)$ & 4 & $(5 \%)$ & \\
\hline Involvment of lymph nodes & 13 & $(2 \%)$ & 12 & $(3 \%)$ & 1 & $(1 \%)$ & 0.483 \\
\hline \multicolumn{8}{|l|}{ Positive surgical margins } \\
\hline \multicolumn{8}{|l|}{ Apical } \\
\hline focal & 53 & $(10 \%)$ & 43 & (9\%) & 10 & $(13 \%)$ & 0.194 \\
\hline extensive & 19 & $(4 \%)$ & 19 & $(4 \%)$ & 0 & $(0 \%)$ & 0.054 \\
\hline \multicolumn{8}{|l|}{ Posterolateral } \\
\hline focal & 44 & $(8 \%)$ & 39 & (9\%) & 5 & $(6 \%)$ & 0.604 \\
\hline extensive & 20 & $(4 \%)$ & 18 & $(4 \%)$ & 2 & (3\%) & 0.454 \\
\hline
\end{tabular}


Table 1 Demographics, preoperative and pathological data (Continued)

\begin{tabular}{|c|c|c|c|c|c|c|c|}
\hline & \multicolumn{2}{|c|}{ Total } & \multicolumn{2}{|c|}{ Evaluated } & \multicolumn{2}{|c|}{ Lost to FU } & \multirow[t]{2}{*}{$p$-value } \\
\hline & $n=$ & & c & & $n=$ & & \\
\hline & & & & & & \multicolumn{2}{|c|}{ Base } \\
\hline focal & 26 & (5\%) & 22 & (5\%) & 4 & (5\%) & 0.840 \\
\hline extensive & 7 & $(1 \%)$ & 7 & $(2 \%)$ & 0 & $(0 \%)$ & na* \\
\hline \multicolumn{8}{|l|}{ Bladder neck } \\
\hline focal & 3 & $(1 \%)$ & 2 & (0\%) & 1 & (1\%) & $n a^{*}$ \\
\hline extensive & 0 & (0\%) & 0 & (0\%) & 0 & (0\%) & $n a^{*}$ \\
\hline
\end{tabular}

*Not applicable, sample size too small

location of PSMs following robot-assisted laparoscopic prostatectomy (RALP) over the inclusion period; (ii) report the rates of $\mathrm{BCR}$ and cancer-related mortality at 2, 5, and 10 years; and (iii) determine if BCR is associated with PSM extent and/or location independently from pathologic stage and Gleason score.

\section{Methods}

\section{Study design}

The authors retrospectively studied the records of all 530 consecutive patients (File1) that underwent RALP, between 2003 and 2012, all performed or supervised by the senior surgeon in a single center (CHR). The inclusion criteria were localized prostate cancer (cT1 to cT3). All patients provided written informed consent for their participation in this study. In addition to their routine follow-up (FU) visits, all patients were contacted to update their records and measure their prostate-specific antigen (PSA) serum levels, between 2015 and 2017. Unless confirmed to be deceased, patients who were not evaluated during this time interval were considered lost to follow-up (LTFU).

\section{Pre-operative evaluation}

Pre-operative data included: age at diagnosis. PSA serum level, biopsy Gleason score and tumour clinical stage (cT) by rectal and imaging examinations (Table 1 ).

\section{Surgical technique}

A 3-arm Da Vinci Surgical System (Intuitive Surgical, Sunnyvale, CA, USA) was used from 2003 to 2006 and was upgraded to a higher definition 4-arm system in January 2007 [20].

\section{Pathological evaluation}

Prostate specimens were fixed in paraffin and prepared following the Stanford protocol [21]. Information collected included: pathologic stage of the tumour (pT), pathologic Gleason score, the presence of PSMs, defined as cancer glands observed at the inked surface of prostate specimens, and lymph nodes invasion $(\mathrm{pN})$. The location of PSMs was defined as either apical, posterolateral, basal or at bladder neck. The extent of PSMs was noted as either focal $(\leq 3 \mathrm{~mm})$ or extensive $(>3 \mathrm{~mm})$.

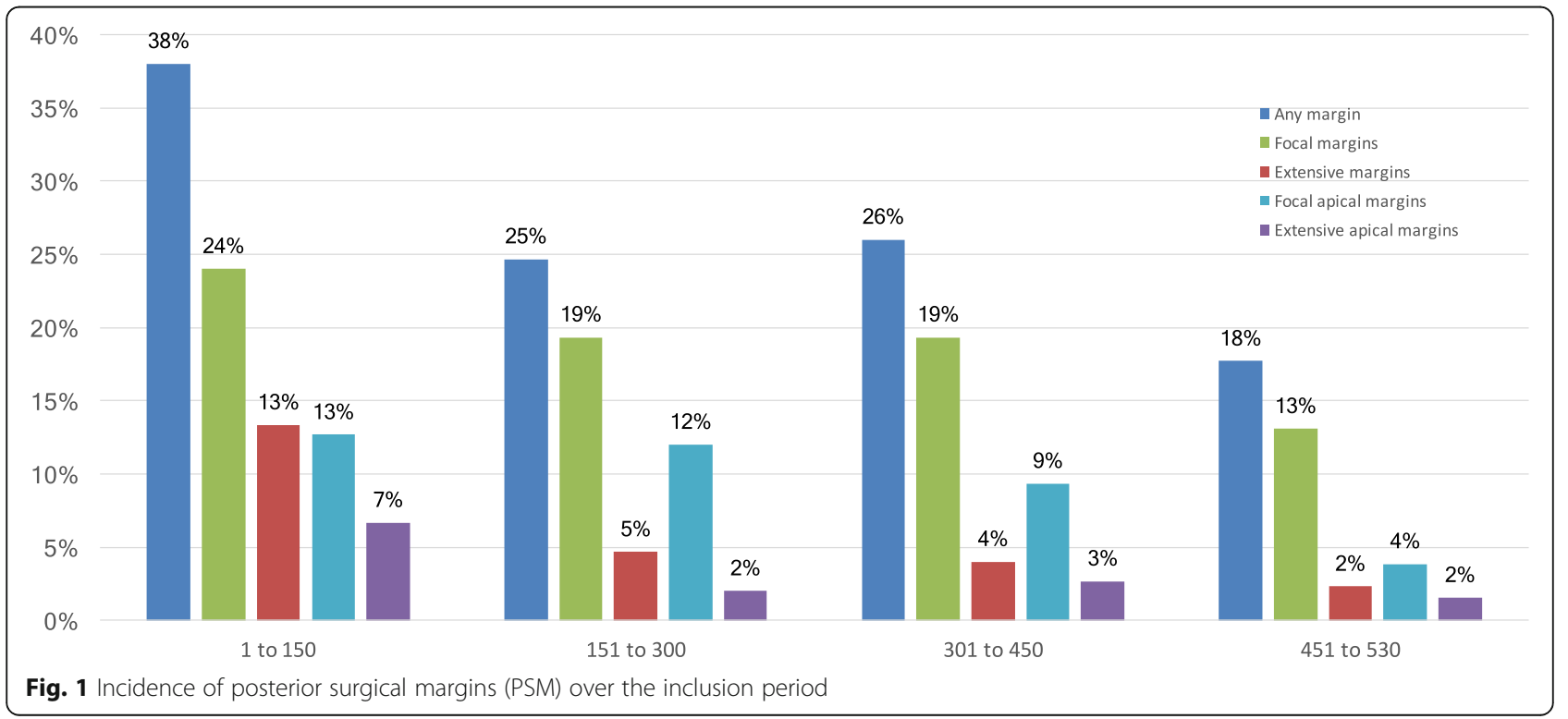




\section{Postoperative follow-up}

For patients with undetectable PSA $(<0.1 \mathrm{ng} / \mathrm{ml})$ at 6 weeks, PSA levels were measured every 6 months in the first 2 years, and once every year thereafter. BCR was defined by PSA $>0.2 \mathrm{ng} / \mathrm{ml}$ confirmed by two successive assays at any point during follow-up. None of the patients received adjuvant treatments, salvage treatments were only considered for patients with BCR.

\section{Statistical analysis}

Categorical variables were described using numbers and percentages. Continuous variables were described using median, 95\% confidence interval (CI) and inter-quartile range (IQR). Differences between patients evaluated after 2015 and those LTFU were assessed using Chi-2 tests or Fisher's exact tests, where appropriate. Kaplan-Meier (KM) survival was estimated at 2, 5 and 10 years for two different endpoints: (i) BCR and (ii) cancer-related mortality. To account for competing risks, the cumulative incidence function was also used and revealed that the KM method exaggerated the incidence of BCR by only $0.8 \%$ at 10 years, which was deemed negligible. Uni- and multi-variable Cox regressions were performed, following the rule of a minimum of 10 events per variable (EPV) [22, 23],to determine associations of BCR with age, preoperative PSA, year of treatment, pathologic Gleason Score $(\leq 6,3+4,4+3$, $\geq 8$ ), stage pT (pT2, pT3a, pT3b, pT4), lymph nodes invasion (none/ metastasized), as well as location and extent of PSM. Variables included in the final multivariable model were identified by backward selection using the Akaike Information Criterion. Statistical analyses were performed using $\mathrm{R}$ version 3.4.1 (R Foundation, Vienna, Austria). The level of significance was set at $p<0.05$.

\section{Results}

For the cohort of 530 patients operated, PSMs were observed in 156 (29\%) patients, of which 18 (3\%) had two or more PSMs (Additional file 1). Out of 172 PSMs, 126 (73\%) were focal and 46 (27\%) were extensive. The location of PSMs was apical in $72(14 \%)$, posterolateral in 64 (12\%), basal in $33(6 \%)$, and at the bladder neck in 3 (1\%) (Table 1). Patients at stage pT3a 57\%) and pT3b/4 (72\%) had a far greater incidence of PSMs than patients at stage pT2 (23\%). The overall PSMs rates decreased from 38 to $18 \%$ over the inclusion period (Fig. 1). A total of 77 patients were lost to FU, leaving 453 for clinical evaluation at a median FU of 92 months (IQR, 87-99). Compared to patients evaluated, those LTFU comprised (Table 1) had similar proportion of high-risk tumors (16\% vs. $19 \% ; p=0.504)$, and of extensive apical PSMs ( $0 \%$ vs $4 \% ; p=0.067)$, but a lower proportion of tumors at pT stage $\geq 3(12 \%$ vs. $28 \%$; $p=0.002)$.
From the cohort of 453 patients evaluated, 138 (30\%) had a BCR, of which $10(2 \%)$ died of causes directly related to prostate cancer, and $9(2 \%)$ died from unrelated causes. Compared to recurrence-free patients, patients who had BCR comprised (i) a higher proportion of pathological Gleason score $\geq 4+3$ (49\% vs. $17 \%$; $p<$ 0.001 ), (ii) a higher proportion of tumors at pT stage $\geq 3$ (53\% vs. $18 \% ; p<0.001$ ), and (iii) a higher proportion of extensive PSMs (20\% vs $5 \%$; $p<0.001)$ (Table 2$)$. Using $\mathrm{BCR}$ as endpoint, the KM survival at 2 years was $0.91(\mathrm{CI}$, $0.88-0.93)$, at 5 years was 0.81 (CI, $0.78-0.85)$ and at 10 years was 0.67 (CI, 0.61-0.72). Using cancer-related

Table 2 Comparison of patients with and without biochemical recurrence

\begin{tabular}{lll}
\hline & $\begin{array}{l}\text { Recurrence-free } \\
n=315\end{array}$ & $\begin{array}{l}\text { Biochemical } \\
\text { Recurrence } n=138\end{array}$ \\
\hline Preoperative data & & \\
Age - median (IQR) & $63.0(58.0-68.0)$ & $64.0(59.0-69.0)$ \\
Preoperative PSA - & $6.0(4.5-8.0)$ & $8.0(5.9-10.9)$
\end{tabular}
median (IQR)

Pathological results

Pathological Gleason Score

$\begin{array}{lll}\leq 6 & 150(48 \%) & 21(15 \%) \\ 3+4 & 113(36 \%) & 46(33 \%) \\ 4+3 & 33(10 \%) & 31(22 \%) \\ >8 & 19(6 \%) & 36(26 \%) \\ \text { unknown } & 0(0 \%) & 3(2 \%)\end{array}$

pT stage

PT2

$259(82 \%)$

62 (45\%)

pT3a

40 (13\%)

35 (25\%)

pT3b

$16(5 \%)$

$36(26 \%)$

PT4

$0(0 \%)$

$2(1 \%)$

unkwon

$0(0 \%)$

$3(2 \%)$

Involvment of

$2(1 \%)$

$10(7 \%)$

lymph nodes

Positive surgical margins

Apical

focal $\quad 29(9 \%) \quad 14(10 \%)$

$\begin{array}{lll}\text { extensive } & 6(2 \%) & 13(9 \%)\end{array}$

Posterolateral

focal $\quad 18(6 \%) \quad 21(15 \%)$

extensive $\quad 7(2 \%) \quad 11(8 \%)$

Base

focal $\quad 11(3 \%) \quad 11(8 \%)$

extensive $\quad 4(1 \%) \quad 3(2 \%)$

Bladder neck

focal $\quad 1(0 \%) \quad 1(1 \%)$

extensive

$0(0 \%)$

$0(0 \%)$ 
mortality as endpoint, the KM survival at 2 years was 1.00 (CI, 1.00-1.00), at 5 years was $0.99(\mathrm{CI}, 0.99-1.00)$ and at 10 years was 0.95 (CI, 0.92-0.98) (Fig. 2).

Univariable Cox regressions revealed $\mathrm{BCR}$ to be significantly associated with age at diagnosis $(p=0.015)$, preoperative PSA level $(p<0.001)$, year of treatment ( $p$ $=0.01)$; pathological Gleason score $(\mathrm{p}<0.001)$, $\mathrm{pT}$ stage $(\mathrm{p}<0.001)$, the lymph nodes invasion $(\mathrm{p}<0.001)$ as well as the presence of focal posterolateral and base PSMs (respectively, $\mathrm{p}<0.001$ and $p=0.003$ ) and extensive apical and posterolateral PSMs (respectively, $p<0.001$ and $p=0.002$ ) (Table 3). Multi-variable Cox regression revealed the strongest predictors of $\mathrm{BCR}$ to be Gleason score $\geq 8(\mathrm{HR}=7.97 ; \mathrm{CI}, 4.38-14.51 ; \mathrm{p}<0.001)$ and $4+3$ $(\mathrm{HR}=3.88 ; \quad \mathrm{CI}, \quad 2.12-7.07 ; \mathrm{p}<0.001)$ compared to Gleason score $\leq 6$, followed by lymph nodes invasion $(\mathrm{HR}=3.42 ; \mathrm{CI}, 1.70-6.91 ; \mathrm{p}<0.001)$, pT stage $3 \mathrm{~b}$ or 4 $(\mathrm{HR}=3.07 ; \mathrm{CI}, 1.93-4.90 ; \mathrm{p}<0.001)$ compared to $\mathrm{pT}$ stage 2, and extensive apical PSMs ( $\mathrm{HR}=2.62$; CI, 1.404.90; $\mathrm{p}=0.003)$ but not focal apical PSMs $(\mathrm{HR}=0.86$; $\mathrm{CI}$, $0.49-1.50 ; p=0.586$ ).

\section{Discussion}

The principal finding of this study was that BCR was independently associated with extensive apical PSMs but not with focal apical PSMs, in addition to Gleason score ( $\geq 8$ and $4+3$ ), lymph nodes invasion, and $\mathrm{pT}$ stage (pT3b/pT4). This observation is important because the prostate apex is the most frequent PSM site for all radical prostatectomy approaches $[24,25]$. There are several explanations as to why focal apical PSMs may be frequent but do not influence oncologic outcomes. First, the proximity of the urethral sphincter, neurovascular bundles and dorsal venous complex renders cancer excision at the apex most challenging for surgeons. Second, the variable configuration of the apex frequently causes iatrogenic intra-prostatic incisions, hypothetically leading to the creation of artefacts or 'false' PSMs [26]. Third, the sparse capsule and periprostatic tissue at the apex makes it difficult for histopathologists to distinguish intra-prostatic from extra-prostatic cancers [1].

Recent studies [27, 28] demonstrated that patients with PSMs have a higher risk of BCR and clinical progression but not necessarily of cancer-specific mortality. At a median follow-up of 92 months (IQR, 87-99), our BCR rate was $30 \%$ and cancer-specific mortality was $2 \%$, both of which are within the range reported in recent studies [3-6, 8, 14, 16-18, 29]. At 10 years, our KM survival was respectively 67 and $89 \%$, using BCR and cancer-specific death as endpoints, respectively.

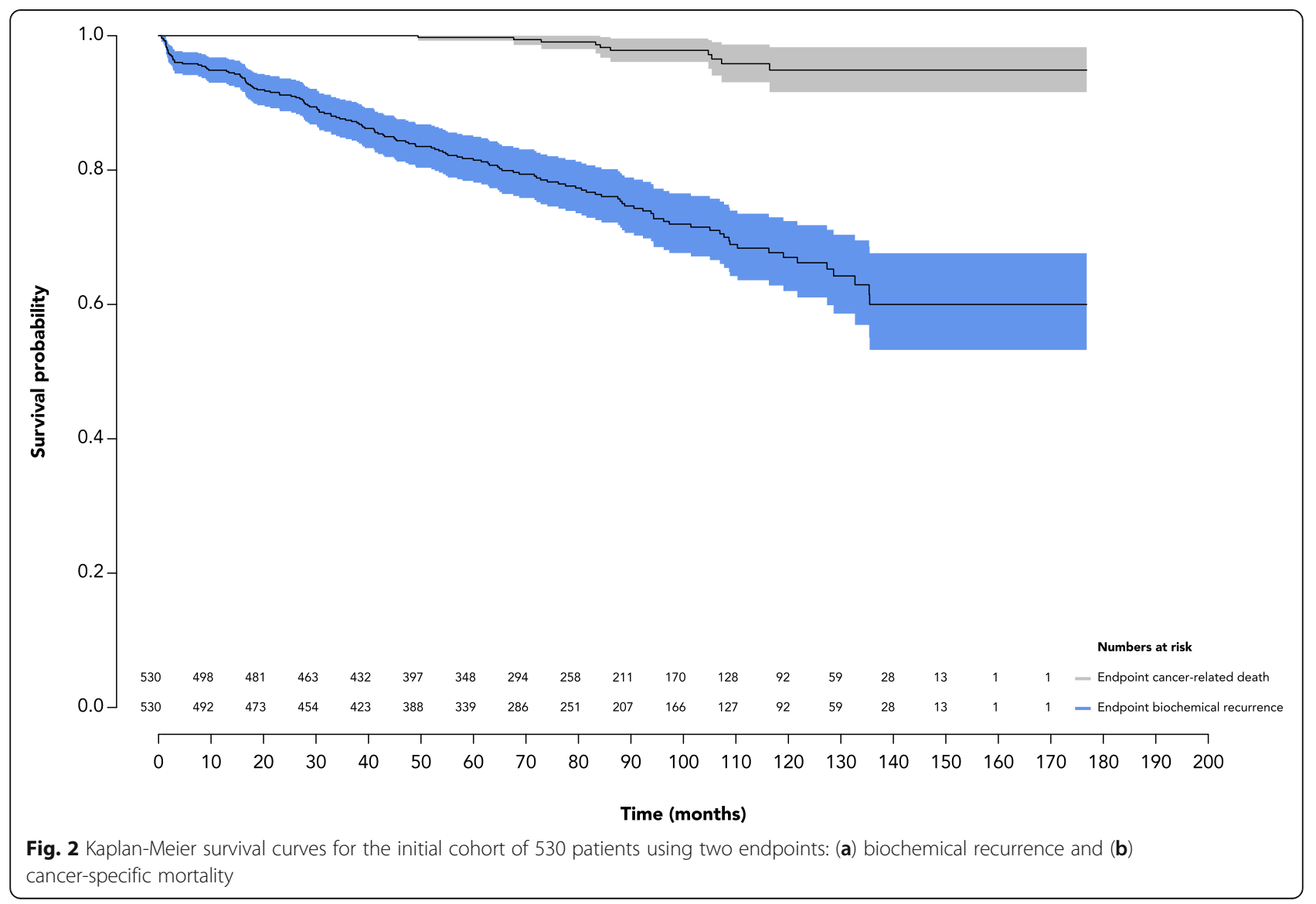


Table 3 Uni- and multi-variable Cox regressions of factors associated with biochemical recurrence

\begin{tabular}{|c|c|c|c|c|c|c|}
\hline & \multicolumn{3}{|c|}{ Univariable } & \multicolumn{3}{|c|}{ Multivariable } \\
\hline & $\mathrm{HR}$ & $95 \% \mathrm{Cl}$ & $p$-value & $\mathrm{HR}$ & $95 \%$ & $p$-value \\
\hline Age & 1.03 & $(1.01-1.06)$ & 0.015 & & & \\
\hline Preop PSA & 1.02 & $(1.01-1.03)$ & $<0.001$ & & & \\
\hline Year of treatment & 1.10 & $(1.02-1018)$ & 0.012 & & & \\
\hline \multicolumn{7}{|l|}{ Pathological Gleason Score } \\
\hline$\leq 6$ & REF & & & REF & & \\
\hline $3+4$ & 3.36 & $(2.00-5.64)$ & $<0.001$ & 2.86 & $(1.68-4.88)$ & $<0.001$ \\
\hline $4+3$ & 7.21 & $(4.13-12.60)$ & $<0.001$ & 3.88 & $(2.12-7.07)$ & $<0.001$ \\
\hline$\geq 8$ & 13.75 & $(7.96-23.74)$ & $<0.001$ & 7.97 & $(4.38-14.51)$ & $<0.001$ \\
\hline \multicolumn{7}{|l|}{ Stage pT } \\
\hline pT2 & REF & & & REF & & \\
\hline рT3а & 3.12 & $(2.06-4.73)$ & $<0.001$ & 2.28 & $(1.48-3.52)$ & $<0.001$ \\
\hline pT3b \& pT4 & 7.37 & $(4.89-11.12)$ & $<0.001$ & 3.07 & $(1.93-4.90)$ & $<0.001$ \\
\hline Involvment of lymph nodes & 8.84 & $(4.57-17.12)$ & $<0.001$ & 3.42 & $(1.70-6.91)$ & $<0.001$ \\
\hline \multicolumn{7}{|l|}{ Apical margins } \\
\hline focal & 1.10 & $(0.63-1.92)$ & 0.742 & 0.86 & $(0.49-1.50)$ & 0.586 \\
\hline extensive & 3.80 & $(2.13-6.77)$ & $<0.001$ & 2.62 & $(1.40-4.90)$ & 0.003 \\
\hline \multicolumn{7}{|l|}{ Posterolateral margins } \\
\hline focal & 2.59 & $(1.62-4.14)$ & $<0.001$ & & & \\
\hline extensive & 2.73 & $(1.46-5.08)$ & 0.002 & & & \\
\hline \multicolumn{7}{|l|}{ Base margins } \\
\hline focal & 2.60 & $(1.40-4.84)$ & 0.003 & & & \\
\hline extensive $^{b}$ & 1.45 & $(0.46-4.58)$ & 0.525 & & & \\
\hline \multicolumn{7}{|l|}{ Neck margins } \\
\hline focal & 1.55 & $(0.21-10.98)$ & 0.67 & & & \\
\hline extensive $^{c}$ & & & & & & \\
\hline
\end{tabular}

${ }^{a}$ Only 2 patients were at stage pT4, both of which had biochemical recurrence

bonly 7 patients had extensive base margins, 3 of which had biochemical recurrence

'None of the patients had extensive neck margins

It has been suggested that apical PSMs occur due to factors other than cancer aggressiveness, although their benign nature remains widely disputed $[5,30]$. Our findings explain this controversy, which is likelydue to lack of distinction between focal and extensive PSMs at the apex. This further demonstrates the importance of adopting a standard method to report PSMs, including their precise extent and location [28]. The finding that focal apical PSMs are not associated with BCR is important, as it could help surgeons improve functional outcomes by sparing the sphincter, and could improve prognosis and decisions regarding additional radiotherapy (RT) $[1,2,9]$. The current rationale for administering local therapy is dichotomous: some advocate adjuvant RT immediately after surgery to all men with PSMs, others advocate salvage RT selectively to men if and when BCR is detected [2]. Our findings suggest that risk of BCR differs depending on PSMs location and extent, which should therefore be taken into account when considering adjuvant RT. In our series, multivariable analysis did not find extensive PSMs at other locations than the apex to be associated with BCR, likely due to the small number of observations in each subgroup. We recorded length of PSMs only as a categorical variable: focal $(<3 \mathrm{~mm})$ or extensive $(\geq 3 \mathrm{~mm})$, [31] though the use of a continuous variable would have been more accurate and objective [32].

For the total cohort of 530 patients, PSMs were observed in 156 (29\%) patients, of which 18 had two or more PSMs. The incidence of PSMs reported in recent radical prostatectomy series varies widely $(12-35 \%)$ [3-6, $8,14,16-18,29$ ], partly due to the large inter-observer variability in identifying PSMs [28], and is also related to surgical experience $[3,6,9,12,13]$. For instance, in their study of 1701 RALPs, Sivaraman et al. [6] described a sharp decrease of PSM incidence from 25 to $20 \%$ after the 
first 350 patients. Sooriakumaran et al. [3] demonstrated continued improvements with increasing surgeon experience, estimating that over 1600 cases are required to decrease PSM rates below 10\%. The observed rates of overall PSMs reduced over our inclusion period (Fig. 1). Extensive PSMs rates decreased drastically, immediately after the first 150 patients, while focal PSMs rates decreased more progressively, possibly due to their greater technical challenge.

The present study is limited by its small cohort size, which could influence our conclusions due to limited statistical power; we however respected the accepted rule of 10 events per variable $[22,23]$ for the Cox model. Although a non-negligible number of patients were lost to $\mathrm{FU}$, they presented a less severe pathological profile (Table 1). Other limitations include lack of report of tumor volume, of Gleason score at PSM and of anterior margins, which were categorized as either basal, posterolateral or apical. Notwithstanding these limitations, the present study comprises a sizeable monocentric RALP series with adequate follow-up and account for surgical experience.

\section{Conclusion}

Our study is the first to investigate the combined effects of PSM location and extent, after robotic assisted radical prostatectomy, and found that the risk of biochemical recurrence increased in the presence of extensive apical margins, independently of pathological Gleason score, pT stage, and lymph nodes invasion. In contrast, the presence of a focal apical margin did not increase the risk of biochemical recurrence. Our findings suggest that adjuvant radiotherapy should only be administered selectively depending on risk factors, including margin location and extent.

\section{Additional file}

Additional file 1: Robotic Assisted Laparoscopic Prostatectomies (RALP) performed from 2003 to 2012. Database of the 530 patients treated by RALP from 2003 to 2012. (XLSX $103 \mathrm{~kb}$ )

\section{Abbreviations}

BCR: BioChemical recurrence; Cl: Confidence interval; CT: clinical stage of the tumor; FU: Follow-up; HR: Hazard ratio; IQR: InterQuartile range; KM: Kaplanmeier; LTFU: Lost to follow-up; PSM: Positive surgical margin; pT: Pathological stage of the tumor; RALP: Robot-assisted radical prostatectomy

\section{Acknowledgements}

The authors are grateful to Mr. Luca Nover for his assistance with data management, tables preparation and reference formatting.

\section{Funding}

MG received a mobility grant from University of Lille-2; AM and GH received fees from ReSurg SA for statistical analysis and manuscript preparation, and CHR was funded by Beaulieu Medical Society (SMB). None of these funding bodies interfered with the study design, data collection, analysis or interpretation of data of this study.

\section{Availability of data and materials}

The datasets analysed during the current study are available from the corresponding author on reasonable request.

\section{Authors' contributions}

GM: Conception and design of the study, data management and statistical analysis, drafting and revising the manuscript, and final approval of the manuscript. AM: Analysis and interpretation of data, drafting and revising the manuscript, and final approval of the manuscript. GH: Analysis and interpretation of data, data management and statistical analysis, drafting and revising the manuscript, and final approval of the manuscript. JR: Acquisition of data, drafting and revising the manuscript, and final approval of the manuscript. JS: Acquisition of data, drafting and revising the manuscript, and final approval of the manuscript. AV: Analysis and interpretation of data, drafting and revising the manuscript, and final approval of the manuscript. MS: Analysis and interpretation of data, drafting and revising the manuscript, and final approval of the manuscript. CHR: Acquisition of data, conception and design of the study, drafting and revising the manuscript, and final approval of the manuscript.

\section{Competing interest}

The author declares that they have no competing interests.

\section{Ethics approval and consent to participate}

All procedures performed in studies involving human participants were in accordance with the ethical standards of the institutional and/or national research committee and with the 1964 Helsinki declaration and its later amendments or comparable ethical standards. Ethics committee approval was obtained from the Commission de Déontologie (Genève). Written informed consent was obtained from all individual participants included in the study.

\section{Consent for publication}

N/A

\section{Publisher's Note}

Springer Nature remains neutral with regard to jurisdictional claims in published maps and institutional affiliations.

\section{Author details}

${ }^{1}$ Urology Department, CHU Lille, F-59000 Lille, France. ${ }^{2}$ University of Lille, GIVRE - MERCS - Module for Education and Research Collaboration in Statistics, F-59000 Lille, France. ${ }^{3}$ ReSurg SA, chemin de la Vuarpillière 35, 1260 Nyon, Switzerland. ${ }^{4}$ Orthopaedic Research Laboratory, Radboud University Medical Center, POBox 9101, 6500HB, Nijmegen, The Netherlands. ${ }^{5}$ Urology Department, Clinique Générale Beaulieu, 1204 Genève, Switzerland.

Received: 8 May 2018 Accepted: 17 December 2018 Published online: 27 December 2018

\section{References}

1. Sooriakumaran P, Dev HS, Skarecky D, Ahlering T. The importance of surgical margins in prostate cancer. J Surg Oncol. 2016;113(3):310-5.

2. Yossepowitch O, Briganti A, Eastham JA, Epstein J, Graefen M, Montironi R, et al. Positive surgical margins after radical prostatectomy: a systematic review and contemporary update. Eur Urol. 2014;65(2):303-13.

3. Sooriakumaran $P$, John M, Wiklund $P$, Lee D, Nilsson A, Tewari AK. Learning curve for robotic assisted laparoscopic prostatectomy: a multi-institutional study of 3794 patients. Minerva urologica e nefrologica The Italian journal of urology and nephrology. 2011;63(3):191-8.

4. Sooriakumaran P, Ploumidis A, Nyberg T, Olsson M, Akre O, Haendler L, et al. The impact of length and location of positive margins in predicting biochemical recurrence after robot-assisted radical prostatectomy with a minimum follow-up of 5 years. BJU Int. 2015:115(1):106-13.

5. Dev HS, Wiklund P, Patel V, Parashar D, Palmer K, Nyberg T, et al. Surgical margin length and location affect recurrence rates after robotic prostatectomy. Urologic oncology. 2015;33(3):109 e7-13.

6. Sivaraman A, Sanchez-Salas R, Prapotnich D, Yu K, Olivier F, Secin FP, et al. Learning curve of minimally invasive radical prostatectomy: Comprehensive evaluation and cumulative summation analysis of oncological outcomes. Urologic oncology. 2017;35(4):149.e1-6. 
7. Seo WI, Kang PM, Yoon JH, Kim W, Chung Jl. Correlation between postoperative prostate-specific antigen and biochemical recurrence in positive surgical margin patients: single surgeon series. Prostate international. 2017:5(2):53-8.

8. Rouanne M, Rode J, Campeggi A, Allory Y, Vordos D, Hoznek A, et al. Longterm impact of positive surgical margins on biochemical recurrence after radical prostatectomy: ten years of follow-up. Scandinavian journal of urology. 2014;48(2):131-7.

9. Matulewicz RS, Tosoian JJ, Stimson CJ, Ross AE, Chappidi M, Lotan TL, et al. Implementation of a surgeon-level comparative quality performance review to improve positive surgical margin rates during radical prostatectomy. J Urol. 2017;197(5):1245-50

10. Basiri A, de la Rosette JJ, Tabatabaei S, Woo HH, Laguna MP, Shemshaki H. Comparison of retropubic, laparoscopic and robotic radical prostatectomy: who is the winner? World journal of urology; 2018.

11. Srougi V, Bessa J Jr, Baghdadi M, Nunes-Silva I, da Costa JB, Garcia-Barreras $S$, et al. Surgical method influences specimen margins and biochemical recurrence during radical prostatectomy for high-risk prostate cancer: a systematic review and meta-analysis. World J Urol. 2017;35(10):1481-8.

12. Damani A, Van Hemelrijck M, Wulaningsih W, Crawley D, Cahill D. Are you now a good surgeon? T2 positive margin status as a quality outcome measure following radical prostatectomy. World J Urol. 2017;35(1):35-43.

13. Park J, Yoo DS, Song C, Park S, Park S, Kim SC, et al. Comparison of oncological outcomes between retropubic radical prostatectomy and robot-assisted radical prostatectomy: an analysis stratified by surgical experience. World J Urol. 2014;32(1):193-9.

14. Pettenati C, Neuzillet $Y$, Radulescu C, Herve JM, Molinie V, Lebret T. Positive surgical margins after radical prostatectomy: what should we care about? World J Urol. 2015;33(12):1973-8.

15. Ploussard G, Drouin SJ, Rode J, Allory Y, Vordos D, Hoznek A, et al. Location, extent, and multifocality of positive surgical margins for biochemical recurrence prediction after radical prostatectomy. World J Urol. 2014;32(6):1393-400.

16. Somford DM, van Oort IM, Cosyns JP, Witjes JA, Kiemeney LA, Tombal B. Prognostic relevance of number and bilaterality of positive surgical margins after radical prostatectomy. World J Urol. 2012;30(1):105-10.

17. Tasci Al, Tufek I, Gumus E, Canda AE, Tugcu V, Atug F, et al. Oncologic results, functional outcomes, and complication rates of robotic-assisted radical prostatectomy: multicenter experience in Turkey including 1,499 patients. World J Urol. 2015;33(8):1095-102.

18. Porpiglia F, Fiori C, Manfredi M, Grande S, Poggio M, Bollito E, et al. Surgical margin status of specimen and oncological outcomes after laparoscopic radical prostatectomy: experience after 400 procedures. World J Urol. 2012:30(2):245-50.

19. Huang JG, Pedersen J, Hong MK, Harewood LM, Peters J, Costello AJ, et al. Presence or absence of a positive pathological margin outperforms any other margin-associated variable in predicting clinically relevant biochemical recurrence in Gleason 7 prostate cancer. BJU Int. 2013;111(6):921-7.

20. Rochat $\mathrm{CH}$, Sauvain J, Dubernard P, Hebert AE, Kreaden U. Mid-term biochemical recurrence-free outcomes following robotic versus laparoscopic radical prostatectomy. J Robot Surg. 2011;5(4):251-7.

21. McNeal JE, Haillot O. Patterns of spread of adenocarcinoma in the prostate as related to cancer volume. Prostate. 2001;49(1):48-57.

22. Austin PC, Allignol A, Fine JP. The number of primary events per variable affects estimation of the subdistribution hazard competing risks model. J Clin Epidemiol. 2017;83:75-84

23. Ogundimu EO, Altman DG, Collins GS. Adequate sample size for developing prediction models is not simply related to events per variable. J Clin Epidemiol. 2016;76:175-82.

24. Meeks JJ, Eastham JA. Radical prostatectomy: positive surgical margins matter. Urol Oncol. 2013;31(7):974-9.

25. Patel VR, Coelho RF, Rocco B, Orvieto M, Sivaraman A, Palmer KJ, et al. Positive surgical margins after robotic assisted radical prostatectomy: a multi-institutional study. J Urol. 2011;186(2):511-6.

26. Walz J, Burnett AL, Costello AJ, Eastham JA, Graefen M, Guillonneau B, et al. A critical analysis of the current knowledge of surgical anatomy related to optimization of cancer control and preservation of continence and erection in candidates for radical prostatectomy. Eur Urol. 2010;57(2):179-92.

27. Stephenson AJ, Eggener SE, Hernandez AV, Klein EA, Kattan MW, Wood DP $\mathrm{Jr}$, et al. Do margins matter? The influence of positive surgical margins on prostate cancer-specific mortality. Eur Urol. 2014;65(4):675-80.

28. Maxeiner A, Magheli A, Johrens K, Kilic E, Braun TL, Kempkensteffen C, et al. Significant reduction in positive surgical margin rate after laparoscopic radical prostatectomy by application of the modified surgical margin recommendations of the 2009 International Society of Urological Pathology consensus. BJU Int. 2016;118(5):750-7.

29. Yuksel M, Karamik K, Anil H, Islamoglu E, Ates M, Savas M. Factors affecting surgical margin positivity in robotic assisted radical prostatectomy. Arch Ital Urol Androl. 2017:89(1):71-4

30. Suardi N, Gallina A, Lista G, Gandaglia G, Abdollah F, Capitanio U, et al. Impact of adjuvant radiation therapy on urinary continence recovery after radical prostatectomy. Eur Urol. 2014;65(3):546-51.

31. Stephenson AJ, Wood DP, Kattan MW, Klein EA, Scardino PT, Eastham JA, et al. Location, extent and number of positive surgical margins do not improve accuracy of predicting prostate cancer recurrence after radical prostatectomy. J Urol. 2009;182(4):1357-63.

32. van Oort IM, Bruins HM, Kiemeney LA, Knipscheer BC, Witjes JA, Hulsbergenvan de Kaa CA. The length of positive surgical margins correlates with biochemical recurrence after radical prostatectomy. Histopathology. 2010; 56(4):464-71.
Ready to submit your research? Choose BMC and benefit from:

- fast, convenient online submission

- thorough peer review by experienced researchers in your field

- rapid publication on acceptance

- support for research data, including large and complex data types

- gold Open Access which fosters wider collaboration and increased citations

- maximum visibility for your research: over $100 \mathrm{M}$ website views per year

At BMC, research is always in progress.

Learn more biomedcentral.com/submissions 